\title{
Sexual dimorphism in the human pelvis: Testing a new hypothesis
}

\author{
H. Correia ${ }^{\mathrm{a}, *}$, S. Balseiro ${ }^{\mathrm{b}}$, M. De Areia $^{\mathrm{a}}$ \\ ${ }^{a}$ Departamento de Antropologia, Universidade de Coimbra, 3000-056 Coimbra, Portugal \\ ${ }^{\mathrm{b}}$ Departamento de Zoologia, Universidade de Coimbra, 3000-056 Coimbra, Portugal
}

Received 14 July 2004; accepted 9 May 2005

\begin{abstract}
Sexual dimorphism in the human pelvis is inferentially related to parturition. Investigators disagree about the identification and obstetric significance of pelvic dimorphism. Benefiting from a large sample of complete skeletons from the Coimbra Identified Skeletal Collection, we show that the dimensions of the true pelvis (birth canal) that are most sexually dimorphic (that is, the dimensions of females are greater than males) are those which are related to biparietal deformation, which often leads to the death of the human neonate. These dimensions are: the anteroposterior diameter of the inlet (index of dimorphism $=108.41$ ), the transverse diameter of the bispinous midplane (index of dimorphism $=117.13$ ) and the transverse diameter of the outlet (index of dimorphism $=112.3$ ). Therefore, sexual dimorphism in the human pelvis is a reflection of differential selection on the two sexes. These results may stimulate further studies with a fresh approach regarding the fossil and comparative evidence for when and how the modern pattern of birth has evolved.
\end{abstract}

(C) 2005 Elsevier GmbH. All rights reserved.

\footnotetext{
*Corresponding author. Rua Dr. Paulo Quintela, 329, Lt 7, 3A, 3030-393 Coimbra, Portugal. Tel.: + 35139085219 ; fax: + 35139085219 .

E-mail addresses: hamilton.correia@clix.pt (H. Correia), sandrabalseiro@clix.pt (S. Balseiro), areia@antrop.uc.pt (M. De Areia).
} 


\section{Introduction}

In humans, the true pelvis is on average larger in females than males, whereas for other measurements of the skeleton, males have greater values than females (Tague, 1992). In both sexes, the pelvis functions in locomotion, posture, visceral support and in adaptation to climate (Abitbol, 1988; Lovejoy, 1988; Ruff, 1991). In females, the pelvis also serves as a birth canal and thus it may be inferred that evolution of pelvic dimorphism is associated with parturition (Tague, 1992).

In Homo sapiens, the size of the foetal cranium and the main diameters of the true pelvis are so similar that the human pelvis is described as "shockingly crowded" in parturition (Schultz, 1949). Two factors have been responsible for this distinctive cephalopelvic proportion, or rather disproportion, in humans. Firstly, the greater size of the foetal neurocranium - there is a strongly positive departure of human neonatal brain mass from a nonhuman primate baseline (Leutenegger, 1982; Harvey and Clutton-Brock, 1985). Secondly, the relatively narrow pelvis subordinated to the demands of efficient bipedalism (Lovejoy et al., 1973). The pelvis in both sexes is under selection due to locomotion, which would favour a narrow pelvis. Additionally, the female pelvis is under selection favouring a wide birth canal and hence maintains enough space to allow for delivery of a viable full term sized foetus (Abitbol, 1987, 1988; Lovejoy, 1988). Cephalopelvic disproportion is a recognised obstetric problem in humans, with a potential risk of mortality to both mother and infant. It is also linked to a number of disorders in infants, including cerebral trauma, mental retardation, and cerebral palsy (Morgan et al., 1986; Connolly et al., 2003).

Due to the large neonatal head size and constraints on the pelvis imposed by bipedal gait, the mechanism of birth in humans is unique (Fig. 1). The foetal head normally engages in the maternal pelvic inlet in a transverse or oblique position. When the foetal head enters the pelvic midplane (between the ischial spines), it is compressed by the narrowing lateral walls of the passage and consequently rotates so that its long axis lies anteroposteriorly. Finally, when the foetal head emerges from the birth canal (outlet plane) it is in an "occiput anterior" position (Trevathan, 1987; Rosenberg, 1992).

Human pelvic dimorphism has been the subject of a number of studies in various scientific disciplines. While researchers agree that certain measures of the pelvis, such as greater sciatic notch angle and subpubic angle, are dimorphic, there remains no consensus in the identification and obstetric significance of other pelvic dimorphic characteristics (for a review, see Tague, 1992).

A study by Borell and Fernström (1958a) revealed that the deformation in the occipito-frontal diameter of the foetal head could occur without harm to the infant. However, another study by Borell and Fernström (1958b) also revealed that the deformation in the biparietal diameter could lead to death of the neonate. Therefore, theoretically, the tighter the fit between the biparietal diameter of the neonatal head and the diameters of the birth canal, the greater are the specialisation of the female pelvis to parturition and the degree of sexual dimorphism in these birth canal diameters. 
A

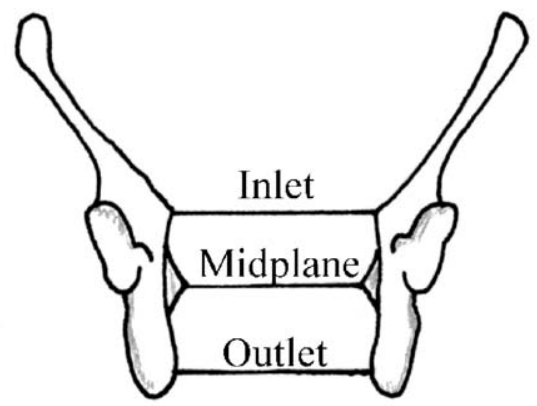

B

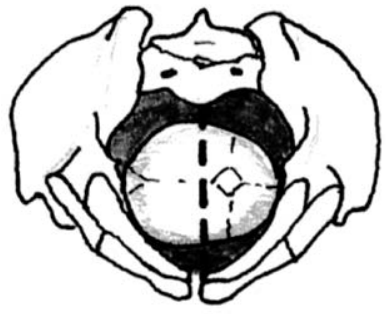

Inlet

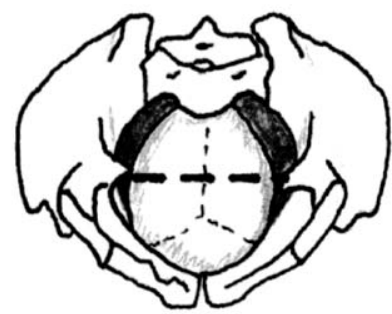

Midplane

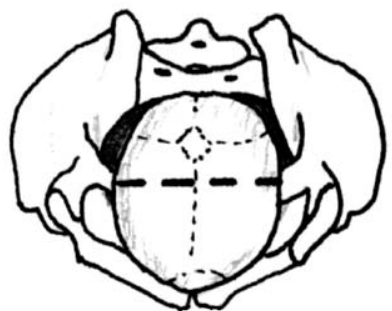

Outlet

Fig. 1. Drawings of true pelvic planes and positions of foetal head in each plane. (A) The human pelvis in coronal section, indicating the positions of the three pelvic planes: inlet, midplane, and outlet. (B) The positions of the foetal head in each plane during labour. The dotted lines represent the true pelvic diameters more sexually dimorphic in each birth canal plane.

In order to test this hypothesis, seven measurements of the true pelvis (birth canal), along with a measurement of femoral length were compared between sexes using a large sample of complete skeletons of the Coimbra Identified Skeletal Collection.

\section{Materials and methods}

\section{The sample}

The true pelvic diameters of males and females from the Coimbra Identified Skeletal Collection were examined and compared. For each of the 505 individuals in the Collection, there was a file with information such as names of the individual and her/his parents, sex, occupation, age at death, place of birth and death, and the cause of death (Arsuaga et al., 1995; Rocha, 1995; Santos, 1995). The individuals died between 1904 and 1936.

For the present study, only the complete skeletons of adult males and females were chosen. A total of 242 individuals (118 males and 124 females) were examined. The 
age of individuals of both sexes varies between 20 and 60 years, with an approximate median age of 37 years. Seven measurements of the true pelvis (birth canal), and a femoral length, were taken for each individual and recorded by the first author.

\section{The measurements}

To facilitate description and for further analysis, the true pelvis was divided into three functional planes, which are considered of clinical or obstetrical importance (Fig. 1A): the inlet (at the iliopectineal line or linea terminalis); the midplane (at the level of the ischial spines); and the outlet (at the level of the ischial tuberosities and the apex of the sacrum). Each pelvis was manually articulated and secured with an elastic band so that there was no movement in the joints. The measurements of true pelvis were taken using a standardised method as described by Tague (1989). Dimensions were measured to the nearest $\mathrm{mm}$ using sliding and spreading calipers. Repeated measurements were very similar. The following pelvic dimensions were taken: (1) anteroposterior diameters: inlet - sacral promontory to dorsomedial aspect of superior pubis; midplane - from transverse line between fourth and fifth sacral vertebrae to dorsomedial aspect of inferior pubis; outlet - apex of fifth sacral vertebra to dorsomedial aspect of inferior pubis; (2) transverse diameters: inlet maximum distance between iliopectineal lines; the diameter is visually aligned to be perpendicular to the anteroposterior; midplane - distance between ischial spines; outlet - distance between ischial tuberosities. (3) In additon, the diagonal diameter of the inlet was measured between iliopectineal lines. For each measurement, the index of dimorphism (ID) was determined. It was defined as the female mean minus male mean times 100 divided by the male mean. The maximum length of the femur was measured to the nearest $\mathrm{mm}$ with an osteometric board. This measure is defined as the distance between the medial condyle and the head. Only the right femora were measured. The data were analysed separately for male and female skeletons.

\section{Results and Discussion}

Statistical parameters of distributions of measured dimensions are given in Table 1. The results of Student's $t$ tests (two-sided) show that, whereas males are significantly larger than females in terms of femoral length $(P<0.0001)$ females are significantly larger than males in terms of the pelvic dimensions $(P<0.0001)$. However, here we have tested the hypothesis that the dimensions of the birth canal along which the biparietal diameter of the foetal head lines up are the ones that should have the greatest sexual dimorphism. This hypothesis is formulated following the suggestion by Borell and Fernström (1958a) that the deformation in the occipitofrontal diameter of the head is less harmful to the neonate than deformation in the parietal diameter. To our knowledge, no other recent studies have confirmed this suggestion. A possible explanation for the lack of reports on this subject is that, in 
Table 1. Summary statistics for pelvic and femoral dimensions $(\mathrm{mm})$ in the Coimbra Collection

\begin{tabular}{|c|c|c|c|c|c|c|c|c|}
\hline \multirow[b]{2}{*}{ Measures } & \multicolumn{3}{|c|}{ Males } & \multicolumn{3}{|c|}{ Females } & \multirow[b]{2}{*}{$t$-value } & \multirow[b]{2}{*}{$\begin{array}{l}\text { Index of } \\
\text { dimorphism }\end{array}$} \\
\hline & $N$ & $X$ & S.D. & $N$ & $X$ & S.D. & & \\
\hline
\end{tabular}

\begin{tabular}{lrrrrrrrr}
\hline $\begin{array}{l}\text { Pelvic dimensions } \\
\text { Anteroposterior diameters }\end{array}$ & & & & & & & & \\
$\quad$ Inlet & 118 & 99.68 & 10.15 & 124 & 108.06 & 9.52 & -6.19 & 108.41 \\
$\quad$ Midplane & 118 & 105.73 & 9.62 & 124 & 112.90 & 9.91 & -5.51 & 106.78 \\
$\quad$ Outlet & 116 & 109.22 & 8.10 & 124 & 116.32 & 9.11 & -6.26 & 106.50 \\
Transverse diameters & & & & & & & & \\
$\quad$ Inlet & 118 & 123.13 & 5.88 & 124 & 130.67 & 8.43 & -8.41 & 106.12 \\
$\quad$ Midplane & 118 & 88.90 & 7.14 & 124 & 104.13 & 9.39 & -13.96 & 117.13 \\
$\quad$ Outlet & 118 & 99.53 & 7.29 & 124 & 111.77 & 9.19 & -11.29 & 112.30 \\
$\quad$ Diagonal inlet & 118 & 118.14 & 5.89 & 124 & 124.94 & 7.44 & -8.05 & 105.76 \\
Body dimensions & & & & & & & & \\
$\quad$ Femur length & 118 & 437.17 & 11.84 & 124 & 391.25 & 10.76 & 20.62 & 89.50 \\
\hline
\end{tabular}

modern societies, the use of the foetal-pelvic index as an indicator of cephalopelvic disproportion (Morgan et al., 1986; Abitbol et al., 1991) has reduced the risk of labour complications. Vaginal birth has often been replaced in cases of predicted cephalopelvic disproportion by caesarean section (Hanzal et al., 1993). This may explain why there are no reports nowadays, of brain damage or neonate death caused by foetal biparietal deformation. An indirect support for the suggestion of Borell and Fernström (1958a,b) is the fact that the cephalopelvic index has been defined as the difference between the median diameter of the midpelvis and the foetal biparietal diameter (Hanzal et al., 1993; Bian et al., 1997). Furthermore, contemporary biomedical practice implicitly supports the important reports of Borell and Fernström (1958a,b). Despite an increase in newborn head circumference being associated with an increase in risk of intrapartum caesarean delivery (Merchant et al., 2001), some physicians believe that caesarean section is absolutely necessary if the biparietal diameter exceeds $100 \mathrm{~mm}$ (Rosenau et al., 1990). Besides, caesarean section is also necessary if there is a smaller true conjugate-foetal biparietal difference (Adadevoh et al., 1989). In short, the ratio between the maternal obstetric conjugate and the foetal biparietal diameter is a critical determinant of whether physicians perceive that vaginal birth is going to be successful (Yasumizu et al., 1994).

According to our hypothesis, we found that, for each of the three planes of the female pelvis, the diameter of the pelvis, which accommodates the biparietal diameter shows greater sexual dimorphism than the diameter that accommodates the foetal occipito-frontal diameter. The dimensions of the birth canal which show greater sexual dimorphism are the anteroposterior diameter of the inlet $(I D=108.41)$, the transverse diameter of the bispinous midplane $(I D=117.13)$ 
and the transverse diameter of the outlet (ID = 112.3) (Table 1). These diameters are precisely the pelvic dimensions, which could lead to a biparietal deformation, due to the internal rotation of the foetal head during the passage through the birth canal (Fig. 1B).

In order to test the significance of our findings, we have analysed whether the pattern of IDs in this sample was consistent with the prediction of our hypothesis. There is a difficulty in considering variation in the index of sexual dimorphism because the index is based on sex specific means and has no sample size or standard deviation. Thus, we have chosen a non-parametric test, the Mann-Whitney $U$ test, for further calculations. The median of IDs of the pelvic diameters which accommodate the foetal biparietal diameter $($ median $=112.30$; lower quartile $=108.41$; upper quartile $=117.13$ ) is significantly different from the median of IDs of the pelvic diameters which do not accommodate this foetal head dimension (median $=106.31$; lower quartile $=105.94$; upper quartile $=106.64)($ Mann-Whitney $U$ test, $P=0.03)$. This result permits us to reject the null hypothesis that there is no difference between the two groups of pelvic diameters, in this sample.

To investigate whether the hypothesised direction of pelvic dimorphism is the same in other samples, we analysed the data of six other samples (two from the Hamann-Todd skeletal collection and four from Amerindian populations) published by Tague (1989) together with the data of the Coimbra sample (Table 2). The median of IDs of the pelvic diameters which accommodate the foetal biparietal diameter (median $=117.37$; lower quartile $=108.78$; upper quartile $=120.63)$ is significantly different from the median of IDs of the pelvic diameters which do not accommodate this foetal head dimension (median $=106.35$, lower quartile $=104.24$; upper quartile $=106.99)($ Mann-Whitney $U$ test, $P=0.0002)$.

It is also interesting to note that at the inlet the pattern is much less clear. In three of Tague's samples, sexual dimorphism at the inlet was stronger in the

Table 2. Index of dimorphism in the six samples from Tague (1989) compared to the data of the Coimbra sample

Index of dimorphisms

\begin{tabular}{llllll}
\hline Whites Blacks & $\begin{array}{l}\text { Indian } \\
\text { Knoll }\end{array}$ & $\begin{array}{l}\text { Pecos } \\
\text { Pueblo }\end{array}$ & Libben & Haida Coimbra \\
& & & & \\
\end{tabular}

\begin{tabular}{llllllll}
\hline $\begin{array}{l}\text { Pelvic dimensions } \\
\text { Anteroposterior diameters }\end{array}$ & & & & & & & \\
$\quad \begin{array}{l}\text { Inlet } \\
\quad \begin{array}{l}\text { Midplane } \\
\text { Outlet }\end{array}\end{array}$ & 108.82 & 114.58 & 104.85 & 100.0 & 96.0 & 108.74 & 108.41 \\
$\quad$ & 107.21 & 108.85 & 104.59 & 106.54 & 104.31 & 115.38 & 106.5 \\
$\begin{array}{l}\text { Transverse diameters } \\
\quad \text { Inlet }\end{array}$ & 103.08 & 104.24 & 107.2 & 106.35 & 101.52 & 102.27 & 106.12 \\
$\quad$ Midplane & 118.6 & 116.87 & 120.43 & 117.86 & - & 129.41 & 117.13 \\
$\quad$ Outlet & 117.6 & 118.95 & 127.0 & 120.83 & 123.30 & 121.57 & 112.3 \\
\hline
\end{tabular}


antero-posterior dimension than in the transverse dimension, contrary to our hypothesis. However, in this plane, the foetal head sometimes engages into an oblique position (Trevathan, 1987; Rosenberg, 1992) and for this reason, the biparietal diameter may not be so constrained. This difference may reflect a variation in birth mechanisms according to pelvic form.

Our suggestion may also explain why such a greater difference between the indices of dimorphism is observed in the midplane and why the bispinous diameter is the most dimorphic pelvic diameter. In this plane, the foetal head is constrained by the narrowing lateral walls and must pass through only when its long axis lays anteroposteriorly. These results suggest that the ischial spines are the most dangerous bony protuberances of the birth canal and are likely to put excessive compression on the foetal biparietal diameter. To our knowledge, there are no clinical data to support this assertion. When childbirth moved from the home to the hospital in the middle of the 20th century, the operative intervention for delivery based on the perception of risk decreased the probability of excessive compression on the foetal biparietal diameter.

These results support the idea that the sexual dimorphism in the human pelvis is a reflection of differential selection on the two sexes. That is, the pelvic sexual dimorphism is directly genetically based or mediated by sex steroid influences on pelvic growth as it has been suggested previously (Tague, 1992).

These results can contribute to our knowledge about mechanisms of birth in Australopithecus and in Homo. A new and comparative analysis of the pelvic dimorphisms in hominid fossils (mainly in the bispinous diameter) may contribute to the understanding of when and how the modern pattern of birth has evolved. For example, using pelvimetric data for A.L. 288-1 and females of H. sapiens (Tague and Lovejoy, 1986), it was possible to observe that the dimensions which accommodate the foetal biparietal diameter in humans are more similar to the respective dimensions of $A$. afarensis than the other pelvic diameters. This similarity suggests that internal rotation of the foetal cranium could be necessary in the A.L. 288-1 pelvis, supporting the idea proposed by Berge et al., (1984) for internal rotation in early hominids. However, this directly contradicts what Tague and Lovejoy (1986) argued, namely, that internal rotation of the foetal head in Australopithecines is not only unnecessary but also impossible.

\section{Acknowledgements}

We thank Paulo Mota, Cristina Padez, Eugénia Cunha and Manuela Alvarez for their helpful advice and the Anthropological Museum at the University of Coimbra for the opportunity to study the Coimbra Identified Skeletal Collection.

\section{References}

Abitbol, M.M., 1987. Obstetrics and posture in pelvic anatomy. J. Hum. Evol. 16, 243-256.

Abitbol, M.M., 1988. Evolution of the ischial spine and of the pelvic floor in the Hominoidea. Am. J. Phys. Anthrop. 75, 53-67. 
Abitbol, M.M., Taylor, U.B., Castillo, I., Rochelson, B.L., 1991. The cephalopelvic disproportion index. Combined fetal sonography and X-ray pelvimetry for early detection of cephalopelvic disproportion. J. Reprod. Med. 36, 369-373.

Adadevoh, S.W., Hobbs, C., Elkins, T.E., 1989. The relation of the true conjugate to maternal height and obstetric performance in Ghanaians. Int. J. Gynaecol. Obstet. 28, 243-251.

Arsuaga, J.L., Lorenzo, C., Carretero, J.M., 1995. Sexual dimorphism of the hip bone in the Coimbra population (Portugal). Antrop. Port. 13, 171-191.

Berge, C., Orban-Segebarth, R., Schmid, P., 1984. Obstetrical interpretation of the australopithecine pelvic cavity. J. Hum. Evol. 13, 573-587.

Bian, X., Zhuang, J., Cheng, X., 1997. Combination of ultrasound pelvimetry and fetal sonography in predicting cephalopelvic disproportion. Chin. Med. J. (Engl) 110, 942-945.

Borell, U., Fernström, I., 1958a. Die umformung des kindlichen kopfes bei engem becken. Geburtsh. Frauenheilkd 18, 1156-1166.

Borell, U., Fernström, I., 1958b. Die umformung des kindlichen kopfes während normaler entbindung in regelrechter hinterhauptslage. Geburtsh. Frauenheilkd 18, 1245-1256.

Connolly, G., Naidoo, C., Conroy, R.M., Byrne, P., Mc Kenna, P., 2003. A new predictor of cephalopelvic disproportion? J. Obstet. Gynaecol. 23, 27-29.

Hanzal, E., Kainz, C., Hoffmann, G., Deutinger, J., 1993. An analysis of the prediction of cephalopelvic disproportion. Arch. Gynecol. Obstet. 253, 161-166.

Harvey, P.H., Clutton-Brock, T.E., 1985. Life history variation in primates. Evolution 39, 559-581.

Leutenegger, W., 1982. Encephalization and obstetrics in primates with particular reference to human evolution. In: Armstrong, E., Falk, D. (Eds.), Primate Brain Evolution: Methods and Concepts. Plenum Press, New York, pp. 85-128.

Lovejoy, C.O., 1988. Evolution of human walking. Sci. Am. 259, 118-125.

Lovejoy, C.O., Heiple, K.G., Burstein, A.H., 1973. The gait of Autralopithecus. Am. J. Phys. Anthrop. 38, 757-780.

Merchant, K.M., Villar, J., Kestler, E., 2001. Maternal height and newborn size relative to risk of intrapartum caesarean delivery and perinatal distress. Biomed J. Obstet. Gynecol. 108, 689-696.

Morgan, M.A., Thurnau, G.R., Fishburne Jr., J.I., 1986. The fetal-pelvic index as an indicator of fetalpelvic disproportion: a preliminary report. Am. J. Obstet. Gynecol. 155, 608-613.

Rocha, M.A., 1995. Les collections ostéologiques humaines identifiées du Musée Anthropologique de l'Université de Coimbra. Antrop. Port. 13, 7-38.

Rosenberg, K.R., 1992. The evolution of modern human childbirth. Yrbk. Phys. Anthrop. 35, 89-124.

Rosenau, L., Grosieux, P., Denis, A., Lahlou, N., Fournis, H., Lebouvier, B., Serra, V., Lepoittevin, L., 1990. Prognostic factors in delivery with breech presentation. Apropos of 357 single-fetus pregnancies at term. Rev. Fr. Gynecol. Obstet. 85, 271-281.

Ruff, C.B., 1991. Climate and body shape in hominid evolution. J. Hum. Evol. 21, 81-105.

Santos, A.L., 1995. Death, sex and nutrition: analysis of the cause of death in the Coimbra human skeleton collection. Antrop. Port. 13, 81-91.

Schultz, A.H., 1949. Sex differences in the pelvis of primates. Am. J. Phys. Anthrop. 7, 401-423.

Tague, R.G., Lovejoy, C.O., 1986. The obstetric pelvis of A.L. 228-1 (Lucy). J. Hum. Evol. 15, $237-255$.

Tague, R.G., 1989. Variation in pelvic size between males and females. Am. J. Phys. Anthrop. 80, 59-71.

Tague, R.G., 1992. Sexual dimorphism in the human bony pelvis, with a consideration of the Neandertal pelvis from Kebara Cave, Israel. Am. J. Phys. Anthrop. 88, 1-21.

Trevathan, W.R., 1987. Human Birth: An Evolutionary Perspective. Aldine De Gruyter, New York.

Yasumizu, T., Nozawa, A., Kinoshita, T., Kato, J., 1994. Trial of vaginal birth following caesarean section for arrest disorders of labor: analysis of patients with well-documented medical records. Asia Oceania J. Obstet. Gynaecol. 20, 407-413. 